\title{
SIDE EFFECTS OF RITUXIMAB IN A PATIENT WITH AUTOIMMUNE MYOCARDITIS DUE TO SJÖGREN'S SYNDROME
}

\author{
Marcel Mathias Villaça ${ }^{1, \star}$, Júlia Boechat Farani ${ }^{1}$, Erika Biegelmeyer ${ }^{1}$, Evelise Mileski do Amaral Berlet ${ }^{1}$, Marília Voges de Souza ${ }^{1}$, \\ Diego Ustárroz Cantali ${ }^{1}$
}

1.Pontifícia Universidade Católica do Rio Grande do Sul, Porto Alegre (RS), Brazil.

*Corresponding author:marcel_mv@hotmail.com.br

\section{BACKGROUND}

Myocarditis is a rare complication of primary Sjögren's syndrome, and the evidence for its treatment is sparse.

\section{CASE REPORT}

We report the case of a 49-year-old black female patient diagnosed with Sjögren's syndrome since September 2018. At first, the manifestations were characterized by nonerosive arthritis of the hands and wrists, xerophthalmia, xerostomia, recurrent parotitis and a lower salivary gland biopsy consistent with the underlying disease. She was initially treated with prednisone $20 \mathrm{mg} /$ day and azathioprine $2 \mathrm{mg} / \mathrm{kg} /$ day. During the clinical evolution, a bronchiolitis obliterans organizing pneumonia and a type 1 renal tubular acidosis developed. Due to the persistence of dyspnea, mainly on exertion, the patient required hospitalization in 2019. The echocardiogram showed a segmental systolic dysfunction with reduced ejection fraction (estimated in $20 \%$ ), but not compatible with coronary heart disease. After cardiologic consultation, the diagnosis of autoimmune myocarditis soon followed. Pulse therapy with methylprednisolone (totaling 2,250 mg) was started, with oral prednisone as the maintenance treatment. Due to the previous failure of treatment with azathioprine and corticosteroid dependency, Rituximab was started. The first cycle of the drug was performed in October 2020, with a dose of 1,000 mg on October 6, 2020 and again on October 20, 2020. No side effects were reported. However, during the first infusion of the second cycle of Rituximab, in May 2021, the patient developed presyncope and chest pain. The infusion was promptly interrupted, only a total of $100 \mathrm{mg}$ was administered, and the patient was admitted to the hospital. A post infusion acute ischemic event was ruled out. On investigation, cardiac magnetic resonance with gadolinium showed delayed enhancement and subepicardial edema in the left ventricle, suggesting myocarditis. A new attempt to administer rituximab was made during hospitalization, with only $300 \mathrm{mg}$ being infused, as the patient developed sweating, chest pain and dyspnea during the procedure. On the following day, she had arthritis of the second and third metacarpophalangeal joints of both hands, which remitted spontaneously over the course of the following days. On every occasion, premedication was instituted with methylprednisolone $100 \mathrm{mg}$, paracetamol $750 \mathrm{mg}$ and dexchlorpheniramine $6 \mathrm{mg}$. Therefore, it was decided not to reintroduce rituximab to this patient on account of the side effects presented.

\section{CONCLUSION}

We report rare side effects of rituximab in a patient with a rare extraglandular manifestation of Sjögren's syndrome.

\section{KEYWORDS}

Rituximab, Myocarditis, Sjögren's syndrome, Side effects. 